\title{
Shock-Wave Properties and Deformation-Induced Structure of Commercial-Purity Titanium
}

\author{
A. V. Pavlenko ${ }^{a}$, A. V. Dobromyslov ${ }^{b}$, N. I. Taluts ${ }^{b}$ *, S. N. Malyugina ${ }^{a}$, and S. S. Mokrushin ${ }^{a}$ \\ ${ }^{a}$ Russian Federal Nuclear Center-Zababakhin All-Russian Scientific Research Institute of Technical Physics, \\ Snezhinsk, Chelyabinsk oblast, 456770 Russia \\ ${ }^{b}$ Mikheev Institute of Metal Physics, Ural Branch, Russian Academy of Sciences, Ekaterinburg, 620108 Russia \\ *e-mail: NinaTaluts@imp.uran.ru \\ Received January 12, 2021; revised April 1, 2021; accepted April 5, 2021
}

\begin{abstract}
The shock compressive wave profiles of commercial-purity titanium samples under different loading conditions have been measured. The spall strength of titanium as a function of the strain rate and temperature of deformation has been found. High-rate plastic deformation mechanisms have been studied. Highrate plastic deformation under the investigated loading conditions has been shown to occur by slip and twinning. The $\alpha \rightarrow \omega$ transformation has been established to begin at $12.2 \mathrm{GPa}$.
\end{abstract}

Keywords: titanium, shock-wave loading, dynamic strength, high-rate plastic deformation, structure

DOI: $10.1134 / \mathrm{S} 0031918 X 2108010 \mathrm{X}$

\section{INTRODUCTION}

A rather large number of works are devoted to the investigation of titanium behavior under shock loading [1-12]. A major part of them deals with the investigation of the mechanisms of plastic deformation and fracture under plane shock-wave loading of commercial-purity VT1-0 titanium. Dynamic yield strength is less sensitive to material composition, structure, and test temperature than yield strength [1]. An increase in temperature from 20 to $600^{\circ} \mathrm{C}$ does not affect the resistance to high-rate plastic deformation [2]. An annealing-induced decrease in dislocation density reduces the hardness of the material, but increases its dynamic yield strength considerably [3]. High-rate deformation results in the formation of shear bands in the fracture region and adiabatic shear bands $[4,5]$.

Impact compression of titanium causes the $\alpha \rightarrow \omega$ transformation. According to different data [6-9], this transformation occurs at different pressures. The pressure depends on impurities in titanium, in particular, the presence of oxygen [8]. The thickness of the sample, the peak shock-wave pressure, the loading technique, and the temperature also affect the transformation pressure.

The majority of the data were obtained from the analysis of complete wave profiles. There are virtually no structural studies of VT1-0 titanium after different loading conditions. The structural data available in the literature are often limited only to X-ray diffraction patterns and optical images $[5,9]$.

Nevertheless, systematic structural studies can improve the importance of the available free-surface velocity profiles. Therefore, this work aims to analyze the free-surface velocity profiles and to analyze the structure and microstructure of VT1-0 titanium samples after shock loading performed at various strain rates in the $\alpha$-phase region.

\section{EXPERIMENTAL}

The object of the investigation was commercialpurity VT1-0 titanium. The total amount of additives in it ( $\mathrm{Si}, \mathrm{Fe}, \mathrm{O}, \mathrm{H}, \mathrm{N}, \mathrm{C}$, other impurities) did not exceed $0.97 \mathrm{wt} \%$.

The shock-wave experiments were carried out with the help of single-stage gas gun with a caliber of $44 \mathrm{~mm}$, at the Russian Federal Nuclear Center-Zababakhin All-Russian Scientific Research Institute of Technical Physics. The collision velocity was measured by the electrocontact technique with an error of $0.2 \%$ [13].

A VT1-0 titanium rod $35 \mathrm{~mm}$ in diameter was the initial workpiece for samples and impactors. The samples were cut perpendicularly to the rod axis. The samples and impactors were cut in the shape of disks with a diameter of $34 \mathrm{~mm}$ and a thickness from 0.3 to $10 \mathrm{~mm}$.

The velocity profiles of the free sample surface were analyzed to find the elastic-plastic properties of the material under study. The free surface velocity profiles were recorded at a time resolution of $2 \mathrm{~ns}$ and a measurement accuracy in the velocity range under study of not less than 1\% using VISAR [14] and PDV [15] laser interferometric techniques.

The collision velocity was changed from 0.35 to $2.00 \mathrm{~km} / \mathrm{s}$. Tests were carried out in the pressure range 




Fig. 1. Structure of VT1-0 titanium in the initial state.

3.9-26.5 GPa and the strain rate range in rarefaction waves $1 \times 10^{5}-3 \times 10^{6} \mathrm{~s}^{-1}$. The temperature of the samples was varied from -108 to $784^{\circ} \mathrm{C}$. The samples were cooled in liquid nitrogen and heated with an induction heater.

The structure of the 4-mm-thick samples was examined. The structure of the samples was examined by X-ray diffraction (XRD) analysis, optical metallography, and transmission electron microscopy (TEM). $\mathrm{X}$-ray diffraction analysis was carried out using a DRON-3 diffractometer with a diffracted-beam graphite monochromator in $\mathrm{Cu} K \alpha$ radiation. Optical metallography was conducted on a Neophot-2 metallographic microscope. Electron microscopic examination was performed using a JEM-200CX electron transmission microscope. Microhardness was measured using a PMT-3M tester at an indentation load of $0.98 \mathrm{~N}$

\section{RESULTS AND DISCUSSION}

According to the $\mathrm{X}$-ray investigation of the phase composition of VT1-0 titanium, it consists of the $\alpha$ phase in its initial state. The diffraction peaks in the XRD patterns are quite narrow, indicating that there are no significant distortions in the structure.

The metallographic examination shows only grain boundaries in the sample (Fig. 1). There is no significant difference in the grain structure in the transverse and longitudinal sections of the initial workpiece. In both cases, the average grain size is $11-13 \mu \mathrm{m}$.

The microhardness in the initial state is $H_{\mu}=$ $1837 \pm 55 \mathrm{MPa}$.

Figure 2 shows the velocity-time profiles of the free surface of the VT1-0 titanium samples (the impact velocity is indicated next to each profile).

The wave profiles with an impact velocity less than $1.0 \mathrm{~km} / \mathrm{s}$ show a splitting of the shock wave into an

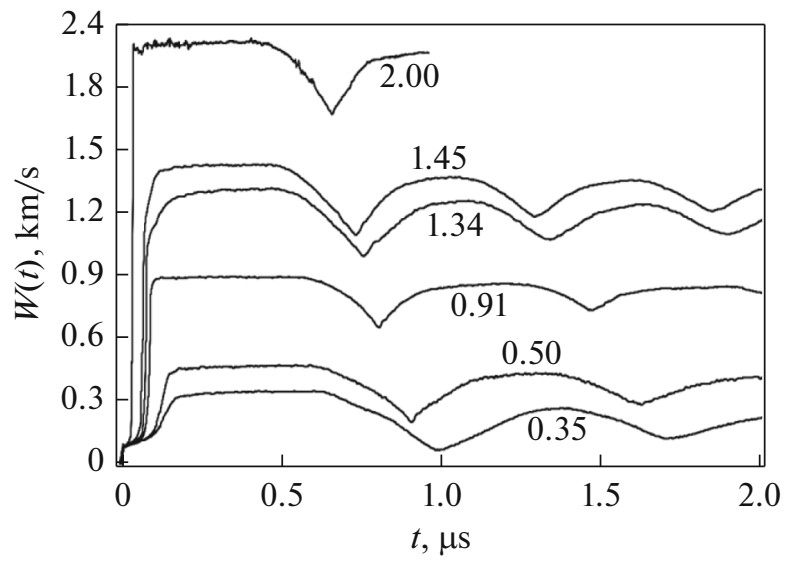

Fig. 2. Velocity profiles of the free surface of the VT1-0 titanium sample were taken at room temperature and at different collision velocities (values are near profiles).

elastic precursor with compression stress behind its front equal to the dynamic elastic limit, and a plastic shock wave. A three-wave configuration of the shock wave exhibiting an $\alpha \rightarrow \omega$ transformation precursor was recorded in experiments at impact velocities of 1.34 and $1.45 \mathrm{~km} / \mathrm{s}$. The $\alpha \rightarrow \omega$ transformation in VT1-0 titanium begins at $12.2 \mathrm{GPa}$. This value agrees quite well with the data of [9]. The velocity of the plastic wave increases naturally with increasing shock compression pressure, whereas the time when the plastic wave reaches the target surface decreases regularly.

The resultant free surface velocity profiles were used to obtain the spall strength and shear stress relaxation in the material under study. The spall strength was calculated using the drop in the free surface velocity during the unloading of the shock-compressed state. The calculation was made taking into account the correction for distortion of the velocity profile due to the difference between the velocities of the spall pulse and the plastic wave in the unloading region [14].

Figure 3 shows the spall strength vs. strain rate of VT1-0 titanium. At low pressures, in the $\alpha$-phase region, the spall strength increases monotonically until the strain rate reaches $7 \times 10^{5} \mathrm{~s}^{-1}$ (indicated by circles and a solid line), at which the spall strength is $\sim 4.3 \mathrm{GPa}$.

The experiments were divided into two groups in the region of high pressures. The first group included the experiments at nearly constant strain rates from $\sim 2 \times 10^{5}$ to $\sim 3 \times 10^{5} \mathrm{~s}^{-1}$. In this group, different completeness of $\alpha \rightarrow \omega$ transformation can be achieved by varying the impact velocity, and the spall strength increases noticeably from $\sim 3.7$ to $\sim 4.9 \mathrm{GPa}(\alpha \rightarrow \omega$ group is indicated by triangles and dotted lines). The second group includes the experiments performed at an impact velocity of $\sim 2.0 \mathrm{~km} / \mathrm{s}$. In this case, $\alpha \rightarrow \omega$ transformation was complete. The spall strength grew 
(a)

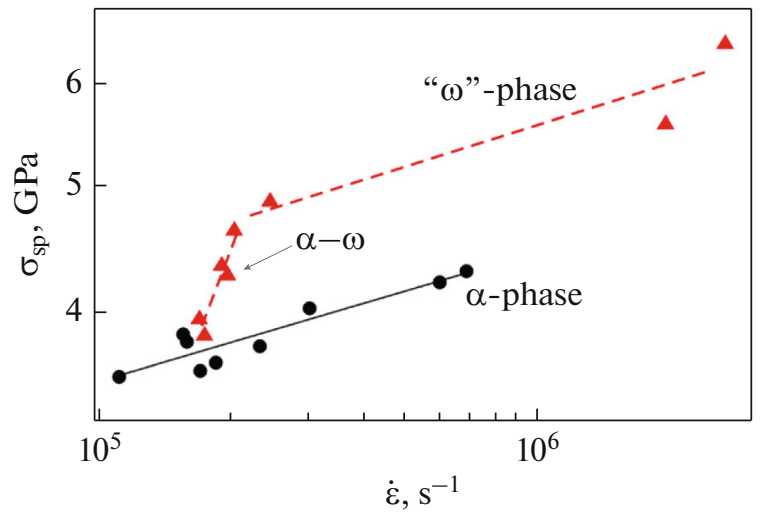

(b)

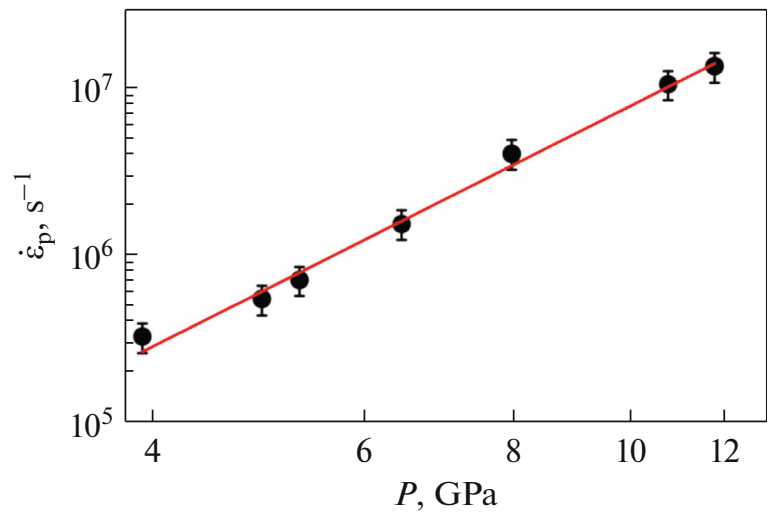

Fig. 3. (a) Spall strength of VT1-0 titanium as a function of the deformation rate and $\alpha \rightarrow \omega$ transformation degree. (b) The maximum deformation rate as a function of the pressure amplitude. Room-temperature loading.

from $\sim 4.9$ to $\sim 6 \mathrm{GPa}$ when the strain rate was increased from $\sim 3 \times 10^{5}$ to $\sim 3 \times 10^{6} \mathrm{~s}^{-1}(\omega$-phase group).

Analysis of the temperature effect showed that the spall strength decreases with increasing temperature. The spall strength at the initial sample temperature of $784^{\circ} \mathrm{C}$ and strain rate of $\sim 2 \times 10^{5} \mathrm{~s}^{-1}$ is $2.4 \mathrm{GPa}$, which is $40 \%$ lower than its value under normal conditions. When the temperature decreases to $-108^{\circ} \mathrm{C}$, the spall strength remains almost the same. In general, these data agree with the results of [10].

The shock-wave loading at impact velocities below $1.0 \mathrm{~km} / \mathrm{s}$ results in a two-wave configuration of the shock wave, the material remains to be an $\alpha$-phase one, and the strain rate increases during shock compression (Fig. 3b). Therefore, the structural studies were carried out on the samples retained after roomtemperature loading at impact velocities $V=0.35$ and $0.57 \mathrm{~m} / \mathrm{s}$; the strain rate increased from $\sim 3 \times 10^{5}$ to $\sim 1 \times 10^{6} \mathrm{~s}^{-1}$.

The loading of VT1-0 titanium at a velocity of $0.35 \mathrm{~km} / \mathrm{s}$ (peak pressure of $3.9 \mathrm{GPa}$ ) forms a spall crack in the cross-section approximately at the middle of the sample thickness. An increase in the pressure to $6.4 \mathrm{GPa}$ at the cost of increasing the impact loading velocity to $0.57 \mathrm{~km} / \mathrm{s}$ increases the cross-sectional size of the main crack significantly. It passes through the middle part of the sample in the same way as it did in the previous case, but the crack is more developed.

Electron microscopic study shows that the pulse impact at $V=0.35 \mathrm{~km} / \mathrm{s}$ results in high-rate plastic deformation of VT1-0 titanium through slip and twinning (Fig. 4). The dislocation structure of the sample is nonuniform. In addition to regions containing a large number of uniformly distributed dislocations (Fig. 4a), there are regions with specific pileups of elongated dislocations. For example, two pileups can be seen in Fig. 4b.

They spread almost parallel to each other. Moreover, some dislocations located between them are also elongated in this direction. These pileups are in fact cross sections of extended planar dislocation pileups.

There are only several regions with microtwins (Figs. 4c, 4d). Typically, almost all these twins contain dislocations inside themselves. Twinning in $\alpha$ titanium during plastic deformation can occur along six planes [16]. The predominant type of twinning depends on both the loading scheme and the temperature of deformation. The twinning planes at room temperature are the $\{10 \overline{1} 2\},\{11 \overline{2} 1\}$, and $\{11 \overline{2} 2\}$ planes. The twinning plane in electron microscopic study is determined by the known direction of its trace on the image and the known axes of the matrix and twin zones. Figure 4d shows the matrix with the [211] zone axis. The absence of all twin reflections makes it impossible to determine its zone axis. Therefore, the twinning plane was found only using the matrix orientation. To do this, we identified the direction of the intersection of all possible twinning planes with the foil plane. A comparison of these directions with the twinning plane trace direction in Fig. 4d shows that only the trace from the (1102) plane coincides with it.

An increase in the impact velocity to $0.57 \mathrm{~km} / \mathrm{s}$ causes a significant increase in the dislocation density as compared to the dislocation density after the low-velocity loading (Fig. 5). The dislocation number density was estimated to be $\sim 10^{16} \mathrm{~m}^{-2}$. The dislocations are distributed mainly homogeneously, but there are regions with a low dislocation density, where dislocations are elongated along crystallographic directions (Figs. 5a, 5b). Similar to the structure formed during the low-velocity loading, the titanium structure in this case exhibits bands with a large number of dislocations (Fig. 5b).

A subgrain structure (Figs. 5c, 5d) forms rapidly under these loading conditions and an increase in the temperature results in partial polygonization.

The number density of microtwins increases slightly in comparison with that under low-velocity 

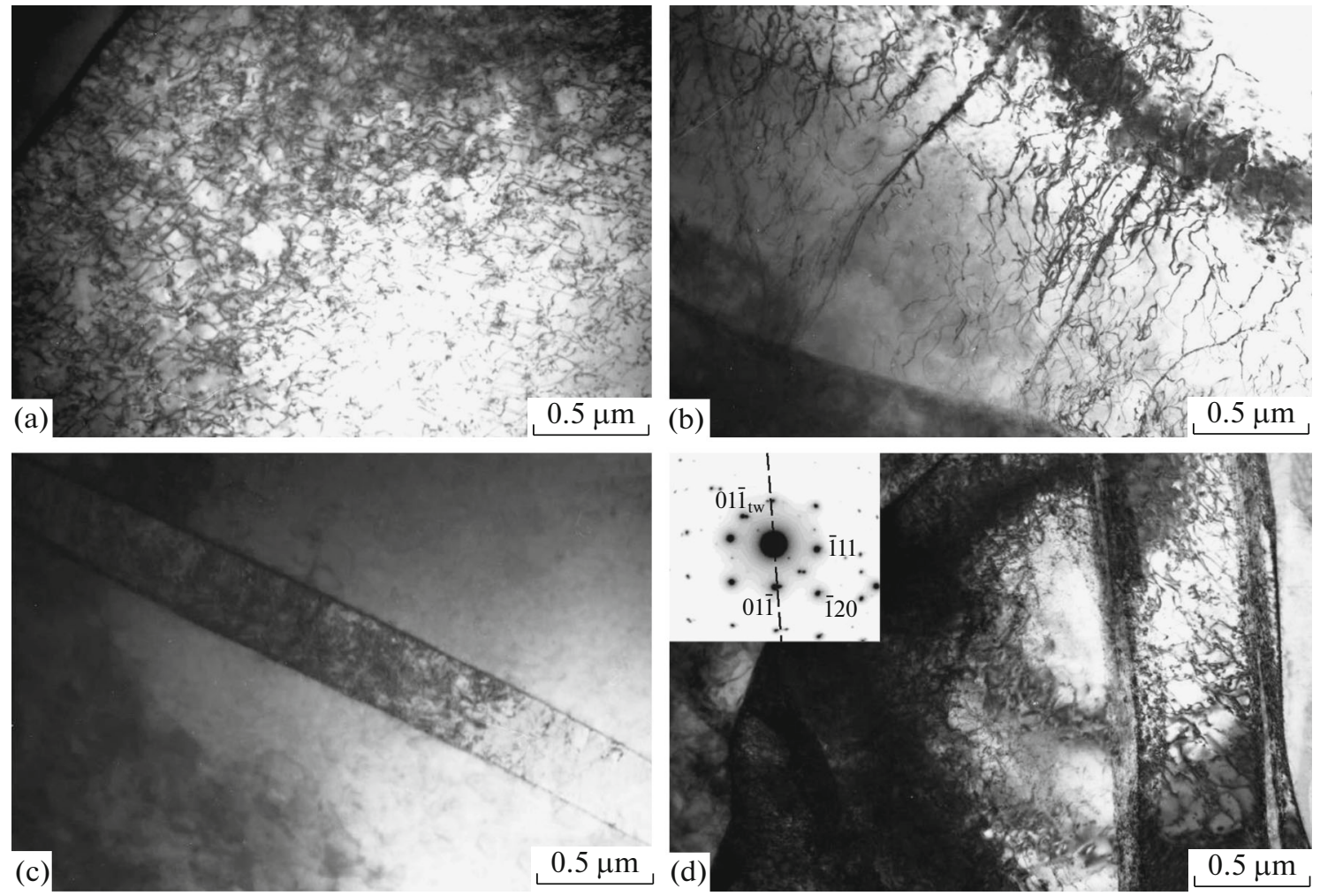

Fig. 4. Microstructure of VT1-0 titanium after pulsed room-temperature impact at $V=0.35 \mathrm{~km} / \mathrm{s}$. The twinning plane is indicated by the dashed line: (a) dislocations, (b) dislocation pileups, and (c), (d) microtwins.

loading (Figs. 5e, 5f). In many regions, microtwins stop growing at the boundaries of the polygonal structure that is being formed.

The microhardness was measured along the cross section of the samples. The microhardness after pulse loading at $V=0.35 \mathrm{~km} / \mathrm{s}$ increases to $2016 \pm 80 \mathrm{MPa}$. The microhardness increment is 9.7\%. The highvelocity loading at $V=0.57 \mathrm{~km} / \mathrm{s}$ increases the microhardness of the alloy to an average value of $2098 \pm$ $69 \mathrm{MPa}$ (by $14.2 \%$ relative to the initial microhardness). After both loading regimes, the microhardness level within the measurement error does not change along the thickness of the disks.

The wave profiles for VT1-0 titanium mainly agree with the data from $[1,3,12]$ obtained under similar loading conditions. In addition, we found that the strain rate-dependent spall strength changes differently at different pressures; namely, it grows monotonically with the strain rate at low pressures, whereas it grows faster at high pressures. This behavior of the spall strength can be attributed to the formation of the $\omega$ phase in this pressure range.

The appearance of the spall cracks indicates that they formed through the nucleation of a large number of pores, their growth, and subsequent pore coalescence.

In contrast to the work [5], the formation of adiabatic shear bands is not observed under the loading conditions we used. Their formation was found [17] to occur at higher shock wave amplitudes.

High-rate plastic deformation occurs by slip and twinning under all loading conditions under the investigation. There are few twins on the microlevel, and their number increases insignificantly with increasing loading velocity. Therefore, slip makes the main contribution to stress relaxation. The dislocation density increases greatly with increasing loading velocity, reaching values exceeding $10^{16} \mathrm{~m}^{-2}$ at impact velocity $V=0.57 \mathrm{~km} / \mathrm{s}$. The dislocation density was noted [18] to be one of the main factors responsible for the formation of a cellular dislocation structure. However, no evidence of the cellular structure formation is detected, despite high dislocation density in the VT1-0 titanium samples under study. This is probably because no fixed Lomer-Cotrell locks are formed in the titanium structure during high-rate plastic deformation. No cellular dislocation structure has been shown [19] to form in the copper single crystal after loading by spherically converging shock waves if there are no fixed Lomer-Cotrell locks in the structure. In titanium, slip mainly proceeds along prismatic and pyramidal planes. The absence of a cellular structure in the investigated samples suggests that slip along these planes does not cause the formation of fixed Lomer-Cotrell locks. 


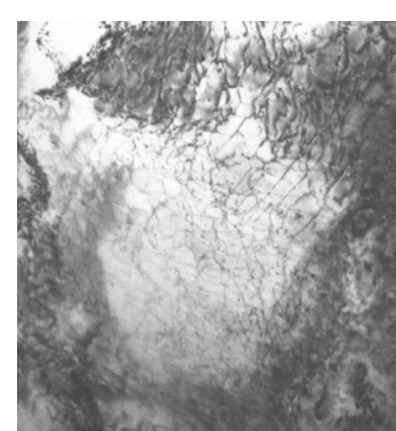

(a)
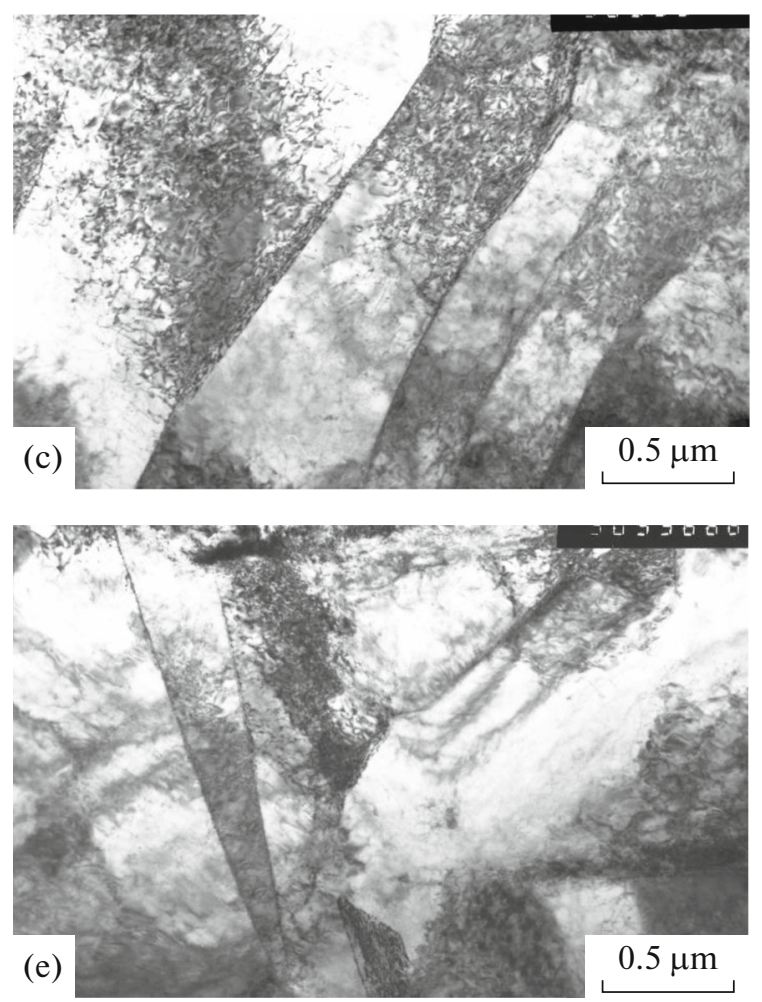

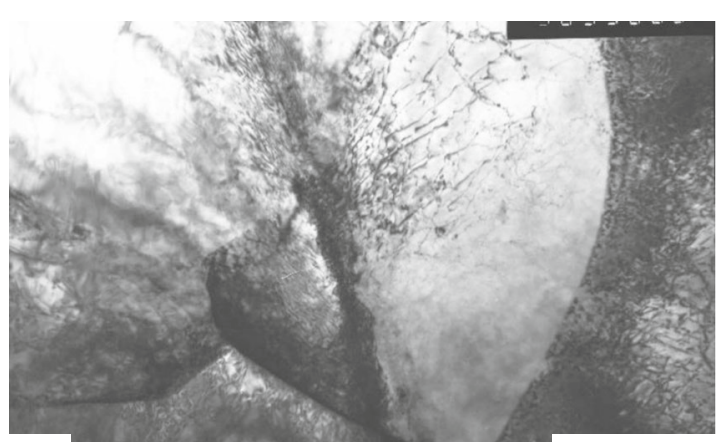

(b)

$0.5 \mu \mathrm{m}$
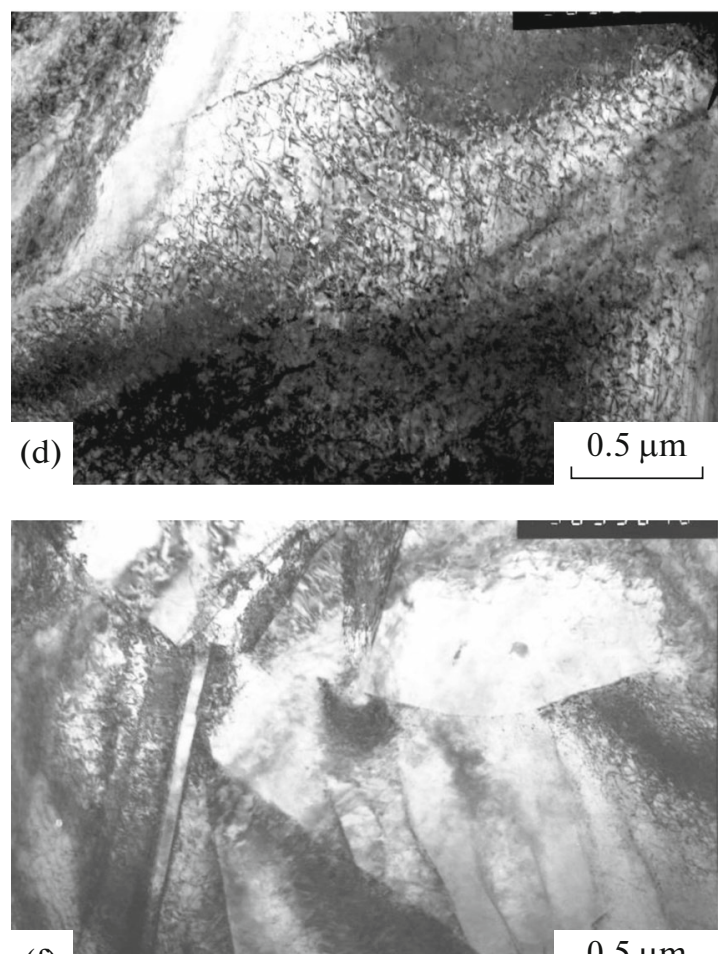

(f)

$0.5 \mu \mathrm{m}$

Fig. 5. Microstructure of VT1-0 titanium after pulsed room-temperature impact at $V=0.57 \mathrm{~km} / \mathrm{s}$ : (a), (b) dislocations elongated along crystallographic directions, (c), (d) subgrain structure, and (e), (f) microtwins.

In addition to uniformly distributed dislocations, there are also plane dislocation pileups in the deformed titanium structure. They form due to densely localized deformation resulted from plastic deformation occurring in several closely located slip planes. The dislocation density in these pileups is very high. Edge dislocations and edge components of mixed dislocations reach grain boundaries when stresses are high, therefore, mainly screw dislocations remain in the localized deformation band, since the velocity of edge dislocations many times exceeds the velocity of screw dislocations.

The spall strength increases with increasing strain rate, due to both a decrease in the tensile stress zone width and an increase in the dislocation density. The spall strength decreases with increasing temperature, because plastic deformation starts at low effective stresses.

\section{CONCLUSIONS}

The effect of shock compression on the rheological properties and deformation structure of VT1-0 titanium was studied.

We found that the $\alpha \rightarrow \omega$ transformation began at $12.2 \mathrm{GPa}$.

The spall strength of titanium depends on the strain rate and changes differently; namely, at low pressures, it grows monotonically with the strain rate, and at high pressures it increases substantially in the $\omega$-phase formation region, depending on the $\alpha \rightarrow \omega$-transformation completeness. 
The recorded dynamic elastic limit and the spall strength decrease at a temperature of $784^{\circ} \mathrm{C}$.

Spall cracks form through the nucleation, growth, and subsequent coalescence of pores.

High-rate plastic deformation under the investigated loading conditions was shown to occur by slip and twinning. Twinning occurs over the $\{10 \overline{1} 2\}$ plane. No adiabatic shear bands were been observed.

\section{ACKNOWLEDGMENTS}

The electron microscopic examination was carried out using a JEM-200CX electron microscope at the Center of the Collaborative Access "Test Center of Nanotechnologies and Advanced Materials," Institute of Metal Physics, Ural Branch, Russian Academy of Sciences.

\section{FUNDING}

This work was performed within the state assignment (theme "Pressure" No. AAAA-A18-118020190104-3) and supported in part by Rosatom (state contracts nos. N.4kh.44.90.13.1111 and N.4kh.44.9B.16.1012).

\section{OPEN ACCESS}

This article is licensed under a Creative Commons Attribution 4.0 International License, which permits use, sharing, adaptation, distribution and reproduction in any medium or format, as long as you give appropriate credit to the original author(s) and the source, provide a link to the Creative Commons license, and indicate if changes were made. The images or other third party material in this article are included in the article's Creative Commons license, unless indicated otherwise in a credit line to the material. If material is not included in the article's Creative Commons license and your intended use is not permitted by statutory regulation or exceeds the permitted use, you will need to obtain permission directly from the copyright holder. To view a copy of this license, visit http://creativecommons.org/licenses/by/4.0/.

\section{REFERENCES}

1. G. I. Kanel, S. V. Razorenov, E. B. Zaretsky, B. Herrman, and L. Meyer, "Thermal "softening" and "hardening" of titanium and its alloy at high strain rates of shock-wave deforming," Phys. Solid State 45, 656-661 (2003).

2. G. I. Kanel, S. V. Razorenov, and G. V. Garkushin, "Rate and temperature dependences of the yield stress of commercial titanium under conditions of shockwave loading,” J. Appl. Phys. 119, 185903 (2016).

3. G. I. Kanel, S. V. Razorenov, G. V. Garkushin, A. V. Pavlenko, and S. N. Malyugina, "Change of the kinetics of shock-wave deformation and fracture of VT1-0 titanium as a result of annealing," Phys. Solid State 58, 1191-1198 (2016).

4. Yu. I. Mescheryakov, A. K. Divakov, N. I. Zhigacheva, and Yu. A. Petrov, "Shock induced phase transformation and mechanisms of spallation in shock loaded titanium alloys,” AIP Conf. Proc. 505, 439 (2000).
5. A. I. Petrov and M. V. Razuvaeva, "Localization of plastic strain under shock-wave loading of titanium alloy with a crack," Tech. Phys. 48, 714-716 (2003).

6. A. R. Kutsar, M. N. Pavlovskii, and V. V. Komissarov, "A two-wave configuration of a shock wave in titanium,” Pis'ma Zh. Eksp. Teor. Fiz. 35 (3), 91-94 (1982).

7. S. V. Razorenov, A. V. Utkin, G. I. Kanel, V. E. Fortov, A. S. Yarunichev, K. Baumung, and H. U. Karow, "Response of high-purity titanium to high-pressure impulsive loading," High Pressure Res. 13, 367-376 (1995).

8. E. Cerreta, G. T. Gray III, A. C. Lawson, T. A. Mason, and C. E. Morris, "The influence of oxygen content on the $\alpha$ to $\omega$ phase transformation and shock hardening of titanium," J. Appl. Phys. 100, 013530 (2006).

9. V. A. Borisenok, M. V. Zhernokletov, A. E. Kovalev, A. M. Podurets, V. G. Simakov, and M. I. Tkachenko, "Phase transitions in shock-loaded titanium at pressures up to 150 GPa," Combust., Explos. Shock Waves (Engl. Transl.) 50, 346-353 (2014).

10. E. B. Zaretsky, "Impact response of titanium from ambient temperature to $1000^{\circ} \mathrm{C}, "$ J. Appl. Phys. 104, 123505 (2008).

11. C. W. Greeff, D. R. Trinkle, and R. C. Albers, "Shockinduced $\alpha-\omega$ transition in titanium," J. Appl. Phys. 90 (5), 2221-2226 (2001).

12. G. I. Kanel', G. V. Garkushin, A. S. Savinykh, and S. V. Razorenov, "Effect of small preliminary deformation on the evolution of elastoplastic waves of shock compression in annealed VT1-0 titanium," J. Exp. Theor. Phys. 127, 337-341 (2018).

13. A. V. Pavlenko, S. I. Balabin, O. E. Kozelkov, and D. N. Kazakov, "A one-stage light-gas gun for studying dynamic properties of structural materials in a range up to 40 GPa," Instrum. Exp. Tech. 56, 482-484 (2013).

14. A. V. Pavlenko, S. N. Malyugina, V. V. Pereshitov, and I. N. Lisitsina, "A VISAR two-channel laser interferometric complex for studying properties of materials under shock-wave loading," Instrum. Exp. Tech. 56, 240241 (2013).

15. S. S. Mokrushin, N. B. Anikin, S. N. Malyugina, A. V. Pavlenko, and A. A. Tyaktev, "An interferometer with time-and-frequency signal compression for studying properties of materials in shock wave experiments," Instrum. Exp. Tech. 57, 475-478 (2014).

16. B. A. Kolachev, Physical Metal Science of Titanium (Metallurgiya, Moscow, 1976) [in Russian].

17. A. Dobromyslov, N. Taluts, and E. Kozlov, "Phase and structure state of titanium loaded by spherically converging shock waves," High Pressure Res. 33, 124-128 (2013).

18. N. A. Koneva, L. I. Trishkina, and E. V. Kozlov, "Cellular dislocation substructures in polycrystals of FCC solid solutions based on copper: Holt's relation and the size effect," Bull. Russ. Acad. Sci., Phys. 76, 12011204 (2012).

19. A. V. Dobromyslov and N. I. Taluts, "Deformation microstructure of a copper single crystal after loading by spherically converging shock waves," Phys. Met. Metallogr. 120, 296-302 (2019).

Translated by T. Gapontseva 